\title{
Information technology practice in cement industry
}

\author{
AHMAD MOH'D MANSOUR* \\ Business Department, Faculty of business \\ Al-Balqa Applied University, As-Salt, JORDAN \\ HANI RA'ED QTAISHAT** \\ Post Graduate in Al-Balqa Applied University, As-Salt, JORDAN \\ ESRA'A JAWDAT SAMARA*** \\ Post Graduate in Jordan University of Science and Technology, JORDAN \\ RAWAN YAHIA AL HUSAMIE**** \\ Post Graduate in Al-Balqa Applied University, As-Salt, JORDAN
}

\begin{abstract}
The aim of this paper was to examine the manner in which Lafarge, a multinational cement corporation, has gone about executing an IT-based strategy. The analysis was motivated by multiple concepts of strategy. Based on currently authorized company framework. The study was done to, evaluate the development process of the ICT-based growth plan for Lafarge cement and to analyse the issues encountered by Lafarge cement in integrating information and communication technologies as a strategic plan.

A standardized questionnaire was used to collect the results. Descriptive figures were used to validate the data's results. The full text discovered that the application of ICT techniques was split down into many levels with numerous sections being allocated to separate divisions and departments. The key players in the development activities were the management who adopted the technologies, external experts and IT workers. There were several planks in the development process, e.g. restricted jobs of method. Because of this, it was not as successful for the lower levels of workers that the ICT approach tackled. It is advised that senior management reduce the amount of administration in the company to move more effectively. There is a need for senior and middle level management to be properly qualified in managing policy execution, and how to effectively deal with different cultures in the enterprise.
\end{abstract}

\section{Keywords: ICT, Jordan, Lafarge Cement, Cement Industry}

Received: January 6, 2021. Revised: April 28, 2021. Accepted: May 5, 2021. Published: May 11, 2021.

\section{Introduction}

It is critical to implement effective Internet technology techniques in order to improve an enterprise's operational and management efficiency. The implementation of information technology would increase the efficiency of an organization's processes. Organizational efficiency can be greatly improved if organizational management strategies take advantage of the benefits of software. One of the primary objectives of an enterprise's technology programs is to improve overall process efficiency. The introduction of the ICT system provides managers with relevant and reliable information to help them make sound decisions. The various ICT approaches should find their proper place within the organization's relevant strategic goals.

Gain a competitive advantage and provide continuous competitiveness to the business by ICT management. The main research areas for this study paper are the most important 
principles and issues in implementing an ICT policy.

\section{Literature Review}

The term information and communication technology (ICT) refers to the transmission of data. In addition to mobile phones, other technology such as radio, television, smart phones, computer and network hardware and software, satellite networks, and video conferencing and distance learning are available. This is the integration of television and telecommunications into a single communications network. ICT allowed improved information mobility and networking. [1]

Given the value of ICT, the LUCC would ensure that it is responsibly managed in order to optimize its effect on the organization. In this regard, we must promote information and communication structures that play an important role in decision-making and interaction. [5] Formal paraphrase

Businesses also struggle because they fail to understand their customers' daily preferences. Strategic ICT preparation is carried out in conjunction with corporate leadership. Corporate experience must be built around meeting the needs of the vertical market.

\section{Definition of Strategic Action}

Everyone knows on the value of business planning but there is no agreement about precisely what strategy is, much less about what it takes to form it. It is seeing better success over competitors. Strategy includes production and capturing of demand of particular product segment. [4] This statement would include the content that people normally are acquainted with.

Lastly, allow policy work by really knowing implementation in an organization. Decisions should be made cautiously because of a plethora of factors. [2] Strategy planning is also viewed as a science because of professionalism. The literature on strategy execution has previously been defined as variable and piecemeal. [7] Many concerns usually emerge during the implementation of programmes. This form of contact would not be as successful if it is not enforced properly by the organization.

Information and Communication Technologies startups are projected to have a major impact on both the economy and culture. [1] Studies also studied startups in order to improve awareness of these organisations and to investigate factors linked to their performance. [2] [5]

According to 2006 White Paper of Chinese Firms, strategic strategy is "the most difficult" for Chinese companies. The survey results found that only 13 percent of the respondents were able to execute an appropriate policy approach. [21]

It is abundantly obvious that the application of legislation will be such a daunting challenge for the culture of today. Implementation should be effective and there are many aspects that affect whether or not an idea can become a reality. If you use the most traditional growth approaches so you will not end up in the debt crisis. Companies in Singapore also fail in pursuing their business plans because of various reasons. Seventy percent of policies and policies crash. There are a lot of misunderstandings about LUCC implementation failure. There are still triggers and motivations that can be understood. Strategies also fail as market is changed by complexities. Products have a shorter product life span, technological technologies emerge more often and the financial markets can be turbulent. Many economies are witnessing tremendous expansion. What Larry Downes has argued is to do with policy execution blunders. Via technology, there is a great shift in the industry. The accomplishment of every large enterprise would begin with an organization's strategy to see out all the requisite capabilities are existent. Ignoring the best interests would negate the scheme. You should take the rivals' objectives into account when developing a marketing plan, since those proposals are part of an annual organizational strategy. We did not take this decision as a matter of personal decisions, it is something that we are both dedicated with and going by it. [12] 
Since so many strategies fail with a lack of buyin, understanding, or insufficient contact, make sure to devote time to providing continual, reliable communication. How recent trends will affect strategy? Connect business results back to the marketing plan. Collaborate with one another to make the project a success. Monitoring and assessment process assists in maintaining the success of every strategy since no one wishes to suffer from disappointment.

\section{ICT-BASED Strategy}

IT plan is a tool that decides how knowledge can be used in an organization. The ICT Strategy is designed to communicate the ICT Agenda among ICT stakeholders externally and internally. An ICT strategy allows balancing technical spending with the corporate goals. ICT business plans are used for buying purposes. Critique initiatives to develop business practices with respect to the aspects of the ICT Strategic Strategy. [3]

This is a kind of ICT strategic strategy that has been carried out for ICT scheme in Singapore. The ICT Framework Strategic Planning aims at developing an accurate and reliable knowledge processing and management system. This will lead to the execution of greater government plans. Information technology implementation planning also entails reviewing ICT procedures, implementing policies, and working to develop processes.

The ICT seeks to examine the current IT climate for accommodation of future demands. So ICT business strategies are very critical to an organization. ICT approaches had a positive impact on company practices. One of the most common subjects in management studies is the question of what it takes to start a successful company. Startup businesses offer a boost to the growth of industries by accelerating developments. Startups also produce innovative goods and services which are unfamiliar at the time of inception and which significantly build upon existing ones and establish new markets. [11] [17]

\section{Cement Manufacturing Industry in Jordan}

Cement is a powder which becomes hard as it sets and hardens into a hard material. Caustic soda is used to produce asphalt and mortar. Cement is made by combining materials like clay, and is then processed through the cementmaking process. Therefore, cement is an important aspect of architecture and building materials. [6] Cement is a raw material indicating the growth in building construction investments. The industry is important as it has a forward and backward linkage with other business sectors, and is a major indicator of the economy as a whole. It is an important source of income to the government as well as important to other fields, including energy. This will lead towards culture, economic and capacity change and growth. [6] According to the results, Jordan's economy grows rapidly. Today, price rises and political uncertainty are a matter of concern in Jordan (post-election violence).

Inflation has significantly harmed the country's GDP. Besides being tightly correlated with economic growth, cement use actually witnessed much faster growth than economic growth during that period. There has been an increase in apartment buildings and cement use as well. In Jordan, cement production started in the 1930s. Blue Circle of United Kingdom is the origin of this firm. Farm produces 800,000 tonnes of steel per year. Lafarge started in 1951 and has been the largest shareholder in Bamburi Cement Ltd. At formation, 140,000 tonnes is the capacity. But in the recent past, the total manufacturing capacity has twice been doubled to 200,000 tonnes (www.bamburicement.com, n.d.). ARM Jordan Co was founded in 1974 by the Paunrama family. At first this firm was a mining company, but in 1990, it ventured into the building industry.

This business plans to generate 200,000 tonnes a year by 2007 (www.armJordan.com, n.d.). Thus, cement production is capital-intensive and energy-intensive. With the environmental conservation sector, we will ensure preservation of the environment. Due to the role of electricity in cement production, it has made such a contribution to global climate change. Cement companies are closely tied to energy 
and transportation (WBCSD, 2002). One of the main problems of the industry sector is to be energy efficient, environmentally friendly and economical (WBCSD, 2002). More factories will be built due to growing demand of cement. Most businesses are aiming for lower electricity and resources prices. Both sectors better themselves and create technologies that improve competitiveness. Factories in the industry are aware of what is legal, and they are not unlawful. There is confusion about this issue (WBCSD, 2002). The daunting problem is how to maximise industry convergence with Cement suppliers to boost environmental concerns. [6] In development of private homes, a number of drivers have boosted this business in a huge way.

The country's Annual Construction Budget is very significant. In this way, the people's per capita demand of cement grew at an average rate of 10.7 percent for the period of 2006 to 2011, up from $50.0 \mathrm{~kg}$ from 2006 due to population growth (KNBS Economic Survey 2009 and 2012). The industry is important as it has a forward and backward linkage with other business sectors, and is a major indicator of the economy as a whole. It is an important source of income to the government as well as important to other fields, including energy. LUCC have considerable impact on economic development in cities and its public wellbeing.

\section{Methodology}

Data collection and research sample Data collection was conducted by the questionnaire. Questionnaire was designed and distributed in electronic form. The questionnaire was distributed to all the offices/plants of Lafarge. Total respondents were 658 but only 600 responses were valid.

\section{Research Objectives}

Our targets for this research were:

i. To evaluate the development process of the ICT-based growth plan for Lafarge cement

ii. To analyse the issues encountered by Lafarge cement in integrating information and communication technologies as a strategic plan.

\section{Value of the Study}

The study is intended to help all persons involved or interested. This research would assist management in determining ICT factors impacting the enterprise and accordingly, establish an IT strategic strategy. Investors are doing more and they should have that sense of the LC project constraints.

The research findings of this study would enable the government to provide a clearer understanding of concerns surrounding the sector. This study may offer new observations that could prove valuable for other researchers. In this way, others will know more about the research subject.

\section{Hypothesis Development}

$H_{1}$ : There is significance difference between adopt and implement and performance

$H_{1 b}$ : There is significance difference between $R \& D$ implement and performance

$H_{1 c}$ : There is significance difference between training and performance

$H_{1 d}$ : There is significance difference between communication and implement and performance

$H_{1 e}$ : There is significance difference between outsourcing implement and performance

$H_{1 f:}$ There is significance difference recruitment and performance 


\section{Analysis}

The analysis aims to determine the knowledge LAFARGE has of its rivals, scale of the company in terms of employee numbers, key advantages LAFARGE has with regard to the cement manufacturing industry in Jordan. This information has been generated to figure out the respondents. $66 \%$ of the respondents had a clear understanding of how many people worked for LAFARGE, while 36\% didn't know what the figure was. This was an optimistic trait of the respondents to this study and the more one is used to how big the organisation is, the more they are likely to require for a successful ICT plan. The research tried to explore if the surveyed respondents were aware of rivals in the cement industry in Jordan.

Table 1. Demographic Details

\begin{tabular}{|c|c|c|}
\hline $\begin{array}{l}\text { "Number of } \\
\text { Employees" }\end{array}$ & "Frequency" & "Percent" \\
\hline “0 - 500" & “0” & “0” \\
\hline “501 - 1000" & "100" & $" 17 "$ \\
\hline “1001-1500" & “400" & "66" \\
\hline "1501 and above" & "100" & $" 17 "$ \\
\hline "Total" & “600" & “100" \\
\hline
\end{tabular}

Table 2. LAFARGE Main Strategic Advantage over their competitors

\begin{tabular}{|l|c|c|}
\hline \multicolumn{1}{|c|}{ "Strategic Advantage" } & "Frequency" & "Percent" \\
\hline "Quality of their Brand" & “400" & "67" \\
\hline "Produce their own clinker" & "200" & "33" \\
\hline "Total" & “600" & “100" \\
\hline
\end{tabular}

$67 \%$ of the respondents felt that Blue triangle remains at the heart of the insurance industry. This is more precisely how the consistency of their concrete has improved over the past 80 years. This makes LAFARGE the most preferred brand in the industry. 33 percent of respondents are optimistic in the element of generating own clinker. Many of their competitors are sourcing coal from abroad at very costly costs. This meant that market name was the vital element of success and the consistency of the cement was an important part of its success in the industry.

\section{The ICT based Strategy Implementation}

The survey of the respondents asked if they heard about the latest ICT-based policy of the LAFARGE and what they think of the introduction. The last thing they covered was their summary of Singapore's ICT strategy.

\section{Table 3. Brief description of the current ICT Based Strategy}

\begin{tabular}{|c|c|c|}
\hline $\begin{array}{l}\text { "Brief description of the } \\
\text { ICT Based Strategy" }\end{array}$ & "Frequency" & "Percent" \\
\hline "Well Defined" & "100" & $" 17 "$ \\
\hline "Poorly Defined" & "200" & “33" \\
\hline $\begin{array}{l}\text { "Didn't know anything } \\
\text { about it" }\end{array}$ & “300" & “50" \\
\hline "Total" & “600" & “100" \\
\hline "ICT Based Strategy" & "Frequency" & "Percent" \\
\hline "New Email System" & “200" & "33" \\
\hline "New ERP System" & “300" & “50" \\
\hline "None" & "100" & “17" \\
\hline "Total" & “600" & “100" \\
\hline
\end{tabular}

As seen in table, most of the respondents were extremely uninformed of ICT related tactics. They did not realise that there is a computerised governance plan in motion. $36 \%$ of respondents offered a bad definition for this approach. Just $17 \%$ of the respondents known and explained the techniques well. This was because he was personally interested in the deployment process and so was well informed about it. This analysis concluded that the implementation phase of ICT was not satisfactory. Next, the researchers found out if some aspect of the Information Communication Technology policy was in progress and if it was effecting or influencing the company. The research discussed ICT based application they have used lately. Table indicates the outcomes of questionnaire.

\section{Table 4. ICT Based Strategy/Changes implemented recently}

\begin{tabular}{|l|c|c|}
\hline \multicolumn{1}{|c|}{ ICT Based Strategy } & Frequency & Percent \\
\hline New Email System & 200 & 33 \\
\hline New ERP System & 300 & 50 \\
\hline None & 100 & 17 \\
\hline Total & $\mathbf{6 0 0}$ & $\mathbf{1 0 0}$ \\
\hline
\end{tabular}


As shown in table, for majority of respondents, the most important ICT related initiative recently introduced was ERP framework. Among the respondents, 33 percent considered Email as a recent technology based high impact strategic initiative. $17 \%$ of the respondents did not know of any ICT driven policy. This research report will concentrate on the utility of the information and communication technologies in relation to the industry. By finding the respondent's opinion on whether ICT department was doing enough in the new ICT sector.

Table 5. Is the ICT department doing enough to remain relevant and supportive

\begin{tabular}{|l|c|c|}
\hline $\begin{array}{c}\text { "Is ICT department } \\
\text { relevant }\end{array}$ & "Frequency & "Percent \\
\hline "Yes & " 600 & " 100 \\
\hline "No & "No & "0 0 \\
\hline "Total & “600 & "100 \\
\hline
\end{tabular}

All of the respondents regarded the ICT department as being in active involvement in their work. It means that they were empowered by ICT and understood that it played a significant role in the sector. Secondly, it must decide avenues for ICT to influence strategic course. In order to assess perceived efficacy of certain application methods, I administered pretest and post-test questionnaire

\section{Table 6. ICT Based Strategy implementations}

\begin{tabular}{|l|c|c|c|c|c|}
\hline \multicolumn{1}{|c|}{ "Implementation Strategy } & $\mathbf{N}$ & Min Max & Mean & $\begin{array}{l}\text { Std. } \\
\text { Dev }\end{array}$ \\
\hline $\begin{array}{l}\text { "Adopt and implement ICT } \\
\text { industry standards }\end{array}$ & 600 & 2 & 5 & 3.00 & 1.265 \\
\hline $\begin{array}{l}\text { "Supporting Research \& } \\
\text { Development in ICT }\end{array}$ & 600 & 2 & 4 & 3.00 & 1.095 \\
\hline $\begin{array}{l}\text { "Promote ICT literacy and } \\
\text { training needs }\end{array}$ & 600 & 2 & 4 & 2.67 & 0.816 \\
\hline $\begin{array}{l}\text { "Well communication of the } \\
\text { ICT Based strategy }\end{array}$ & 600 & 2 & 4 & 2.33 & 0.816 \\
\hline $\begin{array}{l}\text { "Outsourcing most of the ICT } \\
\text { Based initiatives }\end{array}$ & 600 & 2 & 5 & 3.17 & 0.983 \\
\hline $\begin{array}{l}\text { "Hiring competent staff and } \\
\text { consultants }\end{array}$ & 600 & 1 & 5 & 3.00 & 1.414 \\
\hline $\begin{array}{l}\text { "Involving key users of systems } \\
\text { in strategy planning }\end{array}$ & 600 & 3 & 5 & 4.17 & 0.753 \\
\hline
\end{tabular}

Respondents were asked to rate the degree to which different ICT techniques and interventions will be beneficial. According to descriptive statistics, implementation approaches had greater effect as they had a mean of more than three out of five as seen in table. In addition to these policy implementation strategies, the study pointed out that the respondents were optimistic about the improvements brought about by key users of programmes in the strategic planning of the ICT based strategy implementation, well communicating the ICT based strategy in the organisation and the need to educate and develop ICT literacy in the organisation both in the ICT department and the organisation as a whole. These are the techniques we found a best technique. After assessing the overall scenario, the original analysis pointed out crucial places to base the ICT. This question asked the respondents to list out what needs to be changed in the business field where they work.[21]

\section{Table 7. Key ICT strategic areas to boost business}

\begin{tabular}{|c|c|c|}
\hline "ICT strategic areas & "Frequency & "Percent \\
\hline "Network Efficiency and availability & “200 & “33 \\
\hline "Online presence i.e. E-Commerce & “ 100 & “17 \\
\hline $\begin{array}{l}\text { "Portability and ease of access for } \\
\text { customers and sales agents }\end{array}$ & "100 & “ 17 \\
\hline "Business Continuity plans & “6200 & “33 \\
\hline${ }^{6}$ Total & 6600 & “100 \\
\hline
\end{tabular}

As noted in Table 4.8, respondents articulated views of the ICT strategic areas by emphasising 2 main topics. All these things stood at $33 \%$ in percentage terms. Both mobile banking and online payment were the groups that gets more visitors among the customers. These two main factors were well described as crucial by respondents and would certainly improve corporations' results. 


\section{Challenges in implementing ICT based strategy}

The research attempts to locate the main difficulty and limitation in the execution of the ICT-based strategy. The study inquired into the problems encountered by businesses and authorities surrounding the enforce of ICT based strategy. This can be shown in table.

Table 8. Challenges/ Constraints in ICT Based strategy implementation

\begin{tabular}{|l|c|c|}
\hline \multicolumn{1}{|c|}{ "Challenges/ Constraints } & "Frequency & "Percent \\
\hline "Lack of ICT skills and expertise & "100 & "17 \\
\hline "Bureaucracy in the organization & "300 & $" 50$ \\
\hline "Poor Change Management & "100 & "17 \\
\hline "Budget Constraints & "100 & "17 \\
\hline "Total & "600 & "100 \\
\hline
\end{tabular}

From table it can be seen that the greatest obstacle to the execution of ICT policy was the bureaucracy. The hardest barrier encountered by the respondents was the issue of infrastructure growth in ICT, primarily related to tower height. There were several other things listed but they were not a high percentage. This research aims to know ways that the effectiveness of the ICT dependent approach can be improved and how to address the difficulties in implementation The findings are seen in the table below.

\section{Table 9. How to improve strategy implementation}

\begin{tabular}{|l|c|c|}
\hline "Challenges/ Constraints & "Frequency & "Percent \\
\hline $\begin{array}{l}\text { "Improve Communication } \\
\text { of the strategy }\end{array}$ & "200 & "33 \\
\hline $\begin{array}{l}\text { "Make the organization } \\
\text { less bureaucratic }\end{array}$ & "300 & "50 \\
\hline $\begin{array}{l}\text { "Improve on change } \\
\text { management }\end{array}$ & "100 & "17 \\
\hline "Total & “600 & "100 \\
\hline
\end{tabular}

\section{Reliability Analysis}

According to the Nunnally scale, the higher the score the more precise the calculation would be. Reliability means how a system still achieves the same result. Cronbach alpha is a normal indicator of a partnership when reliability of each item is taken into account [4] [3]
Cronbach's alpha value has been estimated to be more than 0.7 , which suggests a broad size. It indicates that the reliability and validity rating is greater than 50\%. For each structure, Cronbach alpha grew higher than accepted standard. [12]

Table 10: Cronbach Alpha

\begin{tabular}{|l|c|c|}
\hline \multicolumn{1}{|c|}{ Construct } & Cronbach Alpha & $\begin{array}{c}\text { Overall } \\
\text { Cronbach Alpha }\end{array}$ \\
\hline Adopt and implement & .813 & \\
\hline $\begin{array}{l}\text { Research \& } \\
\text { Development }\end{array}$ & .732 & \\
\cline { 1 - 2 } Training & .700 & \multirow{2}{*}{.709} \\
\cline { 1 - 2 } Communication & .821 & \\
\hline Outsourcing & .703 & \\
\hline $\begin{array}{l}\text { Hiring competent } \\
\text { staff and consultants }\end{array}$ & .789 & \\
\hline
\end{tabular}

The degree of legitimacy in which a system tests what is expected is referred to. [9] The efficiency of a procedure can be determined by incorporation and exclusion. Inter-item correlation analysis supports convergent validity. As previous researchers have suggested, the correlation values between the sections of our sample were 0.6 to 0.9 [12] Psychometric scale tests have thus ensured the strength and efficiency of the unit. The results show that Cronbach alpha is the greatest element in reliability. The value is usually shown to be a high reliability of 0.6-0.8.

\section{Regression}

Regression is a method used to assess the association between variables. Regression is the measure of the interaction between two variables. Exogenous variables cause the outcomes of the endogenous variable consumer.

The results of this analysis indicate that all theories are supported. The direct influence of public adoption on results is important and substantial. The effect on use of output of the dependent variable is 512 percent. Around the same time, a 1 percent improvement in execution would result in an incredible 512 percent efficiency gain. There is a positive and clear partnership between adopt and introduce about cement industry in Jordan. 
The second prediction is the effect of $R \& D$ on results. An expenditure in $R \& D$ has a great impact on the output of the dependent variable. With 1 percent investment in $R \& D$, one is guaranteed of a 349 percent return on investment. The figure shows positive and clear interaction between the two variables.

The third theory forecasting academic success was not supported. There is simply no proof that contact has a major impact on results. The conclusion revealed that there was no causal association between communication and understanding.

The effect of preparation on results $(\beta=0.016, p=$ 0 . 023). The marginal impact of training on dependent variable output is around 765 percent. Due to a $1 \%$ training impact, a company's efficiency would go up $765 \%$. The p-value indicates a significant association between the variables.

Fifth hypothesis indicates a substantial direct effect of outsourcing on companies $(\beta=0.479$, $\mathrm{p}=.003)$. The effect of outsourcing on success metrics is estimated at 480 percent. A $1 \%$ growth in Outsourcing would see a $479 \%$ boost in efficiency. The figure shows positive and clear interaction between the two variables.

The "impact of recruitment on performance" hypothesis was not endorsed. This suggests that recruitment has little effect on the dependent variable's output. There is no effect on recruiting and efficiency because of the test outcome of $\mathrm{p}=0.384$.

Table 11: Regression Results

\begin{tabular}{|c|c|c|c|c|c|}
\hline $\begin{array}{l}\text { S. } \\
\text { N } \\
\text { o }\end{array}$ & $\begin{array}{c}\text { Independen } \\
\text { t variable }\end{array}$ & $\begin{array}{c}\text { Depende } \\
\text { nt } \\
\text { variable }\end{array}$ & $\begin{array}{c}\text { Coeffici } \\
\text { ent }\end{array}$ & sig & Result \\
\hline 1 & $\begin{array}{l}\text { Adopt and } \\
\text { implement }\end{array}$ & \multirow{6}{*}{$\begin{array}{l}\text { Performa } \\
\text { nce }\end{array}$} & 0.512 & $\begin{array}{c}0.00 \\
0\end{array}$ & $\begin{array}{c}\text { Significa } \\
\text { nce }\end{array}$ \\
\hline 2 & $\begin{array}{c}\text { Research \& } \\
\text { Developmen } \\
\mathrm{t} \\
\end{array}$ & & 0.349 & $\begin{array}{c}0.00 \\
2\end{array}$ & $\begin{array}{c}\text { Significa } \\
\text { nce }\end{array}$ \\
\hline 3 & $\begin{array}{l}\text { Communicat } \\
\text { ion }\end{array}$ & & 0.041 & $\begin{array}{c}0.31 \\
8\end{array}$ & $\begin{array}{c}\text { No } \\
\text { significan } \\
\text { ce }\end{array}$ \\
\hline 4 & Training & & 0.765 & $\begin{array}{c}0.02 \\
1\end{array}$ & $\begin{array}{c}\text { Significa } \\
\text { nce }\end{array}$ \\
\hline 5 & Outsourcing & & 0.479 & $\begin{array}{c}0.00 \\
3 \\
\end{array}$ & $\begin{array}{c}\text { Significa } \\
\text { nce }\end{array}$ \\
\hline 6 & $\begin{array}{c}\text { Hiring } \\
\text { competent } \\
\text { staff and } \\
\text { consultants }\end{array}$ & & 0.078 & $\begin{array}{c}0.38 \\
4\end{array}$ & $\begin{array}{c}\text { No } \\
\text { Significa } \\
\text { nce }\end{array}$ \\
\hline
\end{tabular}

KMO and Bartlett's Test

Table 12: KMO and Bartlett's Test

\begin{tabular}{|c|c|c|}
\hline \multicolumn{2}{|c|}{$\begin{array}{r}\text { Kaiser-Meyer-Olkin Measure of Sampling } \\
\text { Adequacy. }\end{array}$} & $\mathbf{. 9 1 1}$ \\
\hline \multirow{3}{*}{$\begin{array}{c}\text { Bartlett's Test of } \\
\text { Sphericity }\end{array}$} & $\begin{array}{c}\text { Approx. Chi- } \\
\text { Square }\end{array}$ & 17677.641 \\
\cline { 2 - 3 } & $\mathrm{df}$ & 323 \\
\cline { 2 - 3 } & Sig. & $\mathbf{0 . 0 0 0}$ \\
\hline
\end{tabular}

The KMO is a metric used to assess the feasibility of conducting research in order to apply the analytical formula. According to Leech et al., (2006) a KMO value greater than 0.5 is needed for sampling adequacy. According to Table 1, the KMO is 0.921. This study' sample size is broad enough to conduct further research. The Measure of Sphericity of Bartlett is another method for determining the relationship between variables. Based on Bartlett's Sphericity scale, it is significant ( $p$ 0.001). [17] According to Table 1, the predictive ability of the Bartlett test is 0.000 . The association matrix varies depending on the personality of the individual. The rotation of the matrix denotes the closeness of the relationship between the variables. Having high regard for one another is a sign of a healthy relationship. This table displays the results of variables such as adopt and implement, recruiting, scheduling, networking, $\mathrm{R} \& \mathrm{D}$, and outsourcing that have been rotated.

\section{Discussion}

Following a thorough review of all of the findings, the business analysts concluded that "ICT makes the business stand out in the market." One way LUCC is using the ICT approach is by encouraging strategy planning. It was arranged for all team members to prepare. However, this was discovered only during the administration period. Other officials who were not directly involved in the implementation of PIP were consulted on a need-to-know basis. The agency emphasized the use of experts and specialists from related fields of IT-enabled techniques, such as knowledge management, Internet and network, and many others. During the creation process, there were some setbacks. 
The policies and visions of ICT are not communicated within the business, especially to staff lower in the enterprise's hierarchy, and there is a lack of employee involvement in plan creation and execution. The most significant challenge for those involved in the implementation is a perception that bureaucracy in the sector is the most significant barrier to system implementation. This improves the implementation of ICT techniques.

In the manufacturing sector, we see a high dependency on information and communication technology. This is evident with the implementation of the ERP Method. This demonstrates that the ICT approach is consistent with the enterprise-wide strategy of connecting the entire supply chain in order to improve the organization's competitiveness in the market from beginning to end.

The client. A poorly regulated implementation of Information and Communication Technology (ICT) strategy has a direct negative impact on the industry's business performance. This demonstrates the significance of a wellexecuted approach to organizational development. If an ICT strategy is not implemented correctly, the issue would affect all divisions of the company. ICT has changed the efficiency and effectiveness of organizations' processes and procedures as of today. [20]

\section{Conclusions}

LAFARGE's ICT approach is a hybrid. There will be greater emphasis on policy education. It was arranged for all team members to prepare. However, this was discovered only during the administration period. The project will also benefit from the use of information security, networking, and other technology experts. ICT (Information and Communications Technology) is gaining traction in industry because it makes businesses more important. Some negative actions or efforts are impeding the implementation process. In addition, there is insufficient coordination of the ICT strategy from the organization's top staff, as well as a lack of involvement of key staff in the implementation and execution of the ICT strategy. Despite significant failures in ICT policy, ICT staff retained a positive outlook.

The industries that are implementing ICT strategies are facing challenges. The majority of respondents believed that the complexity of ICT strategies was the most significant barrier to the implementation of an ICT-based strategy. They reasoned that if there were less due processes required to start projects or buy goods, it would be much easier for them to resolve their blockade issues. This will go a long way toward accelerating the adoption of ICT-based strategies.

The study also shows managers' and supervisory staff's lack of knowledge about high-level strategies and attempts to develop the company. This involve becoming aware of important organizational changes that are taking place and how they will contribute to the overall success of the effort. Even though they recognized numerous ICT initiatives to boost business and make it more competitive, they still needed more information on the subject to improve support and channeled efforts toward them.

\section{Reference}

[1] Blankson, C., \& Kalafatis, S. P. (2004). The development and validation of a scale measuring consumer/customer-derived generic typology of positioning strategies. Journal of Marketing Management, 20(1-2), 5-43.

[2] Bitpipe. (2001). IT-Industry. Retrieved from http://www.bitpipe.com: http://www.bitpipe.com/tlist/ITIndustry.html

[3] Cyrus S. A. (2013, Febuary). http://www.iiste.org. Retrieved from http://www.iiste.org: http://www.iiste.org/Journals/index.php/EJ BM/article/download/6162/6291

[4] Cronbach, L. J. (1951). Coefficient alpha and the internal structure of tests. psychometrika, 16(3), 297-334. 
[5] De Vellis, J. C. (2003). Patenting industry standards: balancing the rights of patent holders with the need for industry-wide standards. AIPLA QJ, 31, 301.

[6] Fried, Y., \& Ferris, G. R. (1987). The validity of the job characteristics model: A review and meta- analysis. Personnel psychology, 40(2), 287-322.

[7] Hogan, T. P., Benjamin, A., \& Brezinski, K. L. (2000). Reliability methods: A note on the frequency of use of various types. Educational and psychological measurement, 60(4), 523-531.

[8] Livesley M. (2011, June). Information and Communications Technology (ICT) Strategic Planning Guideline. www.services.nsw.gov.au. Retrieved from www.services.nsw.gov.au.

[9] Kimberlin, C. L., \& Winterstein, A. G. (2008). Validity and reliability of measurement instruments used in research. American journal of healthsystem pharmacy, 65(23), 2276-2284.

[10] Michael E. Raynor . (2007, November). What is corporate strategy, really? Retrieved from http://www.iveybusinessjournal.com: http://www.iveybusinessjournal.com/topic s/strategy/what-is-corporate-strategyreally\#.Ue6qm22QwmY

[11] Morton H. (2012, May). http://businessbarbados.com/industries/ict -communications/ict-enhance- businesscompetitiveness/. Retrieved from http://businessbarbados.com/industries/ictcommunications/ict-enhance-business competitiveness

[12] Nunnally, J. C., \& Bernstein, I. H. (1978). Psychometric testing.

[13] Njeru W. (2007). Strategic responses by the cement manufacturing companies in Kenya. Nairobi: Njeru Winston Kinyua. Nairobi, Kenya.

[14] Noble (1999b). Making strategy work. Livingston Bridge, IL, Ohio.
[15] The Effect of Implementing Risk Management Strategies on Supply Chain Performance-A Case of Kenya Medical Supplies Agency . (2013, June). Nairobi, Kenya.

[16] Thiga.S.W. (2002). Strategic Responses by Airlines operating in Kenya to Changes in Environment. Unpublished MBA Project, University of Nairobi. Nairobi, Kenya.

[17] Tobias, S., \& Carlson, J. E. (1969). Brief report: Bartlett's test of sphericity and chance findings in factor analysis. Multivariate behavioral research, 4(3), 375-377.

[18] Uppal, A., Wadhwa, B., \& Vashisht, A. (2018). Magnitudes of Attractiveness in Employer Branding: Generation Z. International Journal of Applied Business and Economic Research, 15(23), 2.

[19] WBCSD. (2002). www.wbcsd.com. Retrieved from www.wbcsd.com: www.wbcsd.com

[20] www.armkenya.com. (n.d.). www.armkenya.com. Retrieved from www.armkenya.com: www.armkenya.com

[21] Yang L. (2008, Febuary). makingstrategy-work. Beijing, Haidian District, China. Retrieved from http://www.knowledgecommunication.org/:http://www.knowledg e-communication.org/pdf/makingstrategy-work.pdf

\section{Creative Commons Attribution License 4.0 (Attribution 4.0 International, CC BY 4.0)}

This article is published under the terms of the Creative Commons Attribution License 4.0

https://creativecommons.org/licenses/by/4.0/deed.en US 